\title{
Isolation and Molecular Characterization of Trichophyton rubrum from Siddi Tribal Community Residing in North Karnataka Region, India
}

\author{
Aruna Chowdappa ${ }^{1}$, Shivakumar Patil ${ }^{2}$, Mahantesh B. Nagmoti ${ }^{3}$ \\ ${ }^{1}$ Department of Microbiology, Jawaharlal Nehru Medical College, KLE Academy of Higher Education and \\ Research, Belagavi, Karnataka, India. ${ }^{2}$ Department of Dermatology, Jawaharlal Nehru Medical College, KLE \\ Academy of Higher Education and Research, Belagavi, Karnataka, India. ${ }^{3}$ Department of Microbiology, \\ Jawaharlal Nehru Medical College, KLE Academy of Higher Education and Research, Belagavi, Karnataka, India.
}

\section{ABSTRACT}

\section{BACKGROUND}

Siddi community is the tribal community of African origin living in north Karnataka region since many generations. Few studies have shown the presence of rare dermatophytes of African origin in the Siddi tribal community. This study was performed to detect the presence of such dermatophytes of African origin in the Siddi community.

\section{METHODS}

A total of 1004 samples were collected from 937 patients with superficial infections out of which 102 samples have shown the dermatophytic growth on culture media. All the dermatophytes were identified by phenotypic and physiological characters.

\section{RESULTS}

Tinea unguium was the prevalent clinical condition and Trichophyton mentagrophytes was the commonest etiological agent to cause dermatophytosis. Two isolates have shown similar macroscopic and microscopic features of as dermatophyte of African origin species (Trichophyton soudanense) and subjected to sequencing of internal transcribed spacer region (ITS) and identified as Trichophyton rubrum.

\section{CONCLUSIONS}

Therefore, presence of rare African species was not seen in the migrated tribal community may be due to the existence of community since more than 5 generations and have adapted to local social and religious practices.

\section{KEY WORDS}

Siddi, Dermatophytes, Trichophyton, Microsporon, Epidermophyton and Tribal
Corresponding Author: Mahantesh B. Nagmoti Department of Microbiology, Jawaharlal Nehru Medical College, KLE Academy of Higher Education and Research, Belagavi, Karnataka, India. E-mail:drmbnagmoti@gmail.com

DOI: $10.14260 /$ jemds/2020/480

How to Cite This Article:

Chowdappa A, Patil S, Nagmoti MB. Isolation and molecular characterization of trichophyton rubrum from siddi tribal community residing in North Karnataka region, India. J. Evolution Med. Dent. Sci. 2020;9(31):2208-2211, $10.14260 /$ jemds $/ 2020 / 480$

Submission 09-05-2020,

Peer Review 24-06-2020,

Acceptance 30-06-2020,

Published 03-08-2020.

Copyright (C) 2020 JEMDS. This is an open access article distributed under Creative Commons Attribution License [Attribution 4.0 International (CC BY 4.0)] 


\section{BACKGROUND}

Dermatophytosis is the superficial fungal infection which mainly affects hair, nail and skin. Dermatophytes produce similar clinical symptoms which are difficult to be distinguished by clinical examination, and these infections are commonly known as tinea infections which are classified based on the site of involvement.(1) There are three ecological group of dermatophytes are known they are anthropophilic, zoophilic and geophilic. Anthropophilic species spreads from human to human and are confined to host. Animals serve as host for zoophilic species and spreads from animals to human. Geophilic species spreads from soil to human.(2) Distribution of the dermatophytes are depends on the geographic location, migration, climate condition, Immune status of the host, socioeconomic condition and age.(3,4) This superficial fungal infection is caused by three genera namely Trichophyton, Microsporon and Epidermophyton; of these Trichophyton is most common, which has 15 species and many verities found within the species.(1) Trichophyton has considerable variation in their morphology as well as in geographical distribution. $T$. rubrum can be seen in many part of the world whereas Trichophyton violaceum, and T. soudanense found in transSudan belt and central African regions. $(1,5,6)$

Siddis are the tribal group having African ancestry brought to India during the $16^{\text {th }}-19^{\text {th }}$ century by Portuguese and residing in Indian states like Gujarat, Karnataka, Andhra Pradesh, and Telangana.(7,8) In Karnataka Siddis are distributed in Uttar Kannada District, although Siddi are residing in India since many generations and adapted to local and social lifestyle they form separate physical and genetic makeup compared to native Indians. $(9,10)$ Several previous study suggested that Siddi genomes have closest relation to the Africans. (7,8) Few literature have shown the existence of rare geographically restricted African origin dermatophytes in the community. $(9,10)$ In the present study we screened Siddi tribal population to see the presence of rare geographically restricted dermatophytes.

\section{METHODS}

The study was conducted during 2015 to 2017 in north Karnataka region with the approval from institutional ethical committee (KLE/Ethic/2015-16/D-51). A total of 1004 samples were collected from 937 Siddi tribal population with suspected superficial fungal infection with required clinical details. Further all samples were subjected to direct microscopy by using $10 \%$ potassium hydroxide $(\mathrm{KOH})$ and inoculated on to Sabouraud dextrose Agarose (SDA) (Himedia) with cycloheximide $(0.5 \% \quad 0.5 \quad \mathrm{mg} / \mathrm{ml})$, chlortetracycline $(0.1 \% 0.1 \mathrm{mg} / \mathrm{ml})$ and Gentamicin $(0.1 \% 0.1$ $\mathrm{mg} / \mathrm{ml}$ ). Inoculated plates were incubated for 4 weeks after inoculation before designating the sample as no growth at $28^{\circ} \mathrm{C}$. Identification of dermatophytes were done on the basis of Macroscopic and Microscopic features and urease hydrolysis.

\section{DNA Extraction, PCR and Sequencing}

Genomic DNA was extracted by phenol-chloroform isoamyl alcohol method as previously described (15) and eluted with $50 \mu \mathrm{l}$ Tris-EDTA buffer. Amplification was carried out by polymerase chain reaction (PCR) using internal transcribe spacer (ITS); ITS 1 and ITS 4 primer (ITS1, 5' TCCGTAGGTGAACCTTGCGG 3', and ITS 4, 5' TCCTCCGCTTATTGATATGC 3'), amplification was done with final volume of $50 \mu \mathrm{l}$ containing $0.5 \mu \mathrm{g}$ of template DNA, $20 \mu \mathrm{l}$ of Emerald Amp GT PCR Master Mix (2X premix composed of a DNA polymerase, optimized reaction buffer, dNTPs, and a density reagent) 15 pmol of each primer. PCR was performed in a thermo cycler (Eppendorf) with initial denaturation of $94^{\circ} \mathrm{C}$ for 6 minutes followed by 35 cycles of $94^{\circ} \mathrm{C}$ for 30 seconds, $58^{\circ} \mathrm{C}$ for 30 seconds and $72^{\circ} \mathrm{C}$ for 1 minute 30 second and final extension at $72^{\circ} \mathrm{C}$ for 10 minutes. Separation of PCR products were carried out on $1.5 \%$ agarose gel stained with ethidium bromide followed by visualized in UV transilluminator and imaged. PCR product were subjected to sequencing both strands using ITS 1 and ITS 4 primer and Big Dye Terminator Cycle sequencing kit version 3.1 (Applied Biosystems), ABI 3130 genetic analyzer (Applied Biosystems) and analysis of all sequencing reaction. Sequences were compared with the GenBank DNA database using the NCBI BLAST tool (https://blast.ncbi.nlm.nih.gov), the ISHAM ITS database

(http://its.mycologylab.org/BioloMICSSequences.aspx), and the CBS database

(http://www.westerdijkinstitute.nl/Collections/BioloMICSSe quences.aspx).

\section{Phylogenetic Analysis}

Phylogenetic analysis of standard sequences retrieved from NCBI and study isolates were carried out by aligning sequences using multiple sequence alignment mode in ClustalX2 software. The aligned sequences were exported to Molecular Evolutionary Genetics Analysis software version 7 (MEGA7).(11) Neighbor joining tree was constructed with 1000 bootstrapping replicates by using Kimura 2 parameter model

\section{RESULTS}

A total of 937 patients were screened for superficial fungal infection, a total of 102 samples showed positive by both microscopy and culture from 90 patients for dermatophytes. Dermatophytes isolated are T. mentagrophytes [69 (67.64\%)], T. rubrum [24 (25.49\%)], Trichophyton tonsurans [3 (2.94\%)], Microsporum gypseum [3 (2.94\%)] and Trichophyton terrestre [1 (0.98\%)]. In the present study two isolates have shown the macroscopic and macroscopic feature of dermatophyte of African origin, isolated from nine year old child who was suffering from tinea capitis since one month had history of soil and animal contact, lesions were spreading without any erythema and a fourteen year old girl with tinea unguium since one month with history of soil and animal contact. Both patients did not have history of antifungal treatment as well as self-medication. 


\section{Mycological Characters}

One isolate shown slow growing growth after 9 days the colonies were waxy glabrous white without any macroconidia and microconidia the colony characters and microscopy were overlapping with the T. rubrum. Another strain was also slow growing, colony was flat and whitish suede-like texture later colony turned to yellow-orange in colour and microscopically no conidia, reflective branching was seen rarely.

\section{PCR and Its Sequencing}

Two phenotypically suspected dermatophytes of African species were sequenced and identified as T. rubrum (accession no: MT280227 and MT280226).

Phylogenetic analysis was done with the study isolates and standard CBS stains retrieved from the NCBI database [ $T$. violaceum CBS 374.92 (NR_144901), T. soudanense IHEM 19751 (NR_155948) and T. rubrum CBS 392.58 (MH857821)] T. Mentagrophytes (KY761968) was taken as out-group. Both the isolate clustered with CBS reference strain T. rubrum.

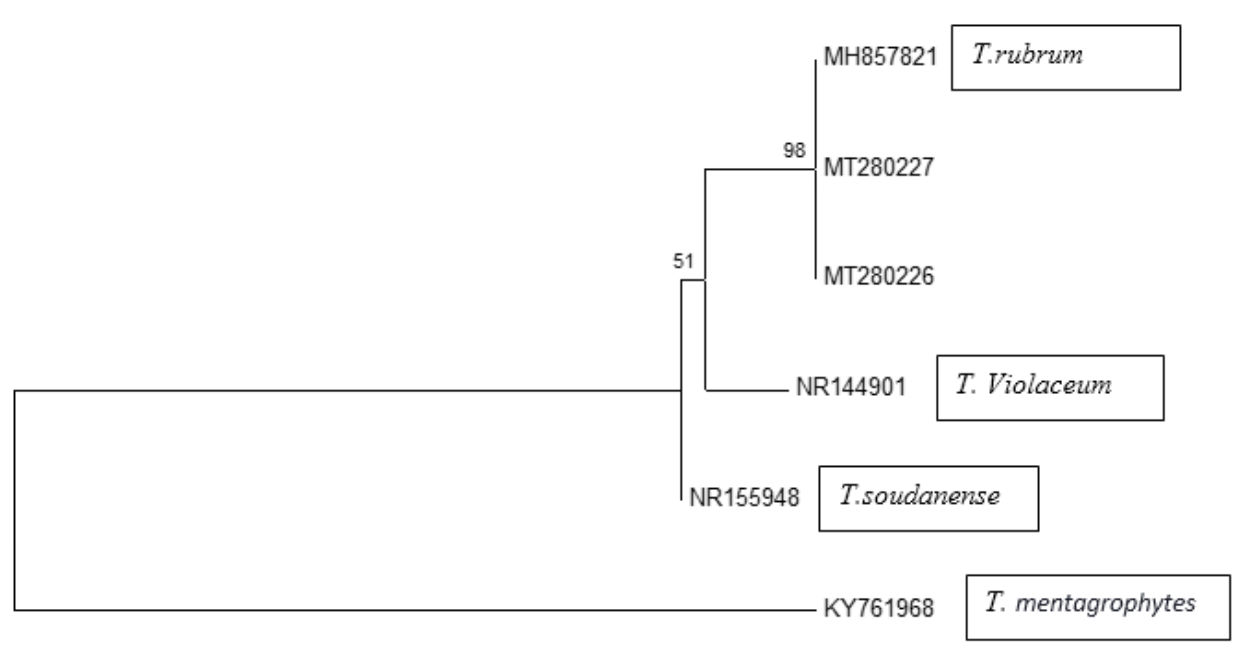

0.0100

Figure 1. Neighbour-Joining (NJ) derived dendrogram of Internal Transcribe Spacer (ITS) gene-based sequences. Phylogenetic analysis was done with the study isolates and standard CBS stains retrieved from the NCBI database. (Trichophyton violaceum CBS 374.92 (NR_144901), Trichophyton soudanense IHEM 19751 (NR_155948), and Trichophyton rubrum CBS 392.58 (MH857821). Trichophyton mentagrophytes (KY761968) was taken as out-group. All isolates are clustered with T. rubrum

\section{DISCUSSION}

Siddi community is the tribal community residing in many parts of India who has African origin and residing in India since more than five generations. ${ }^{(9,12)}$ Investigators in India have shown the presence of rare dermatophytes of African species in the Siddi tribal community. Hemashettar and Nadigir isolated T. soudanense in 1980 and in 1993 Hemashetter isolated Trichophyton yaoundei in the community. $(9,10)$ Few literature around the world have shown the presence of such infection in the native and African origin population.(5,6,13-16) To see the presence of such rare dermatophytes of African species we have screened more than 2000 Siddi community persons residing in the north Karnataka region of India. Out of 1004 samples 102 samples have grown dermatophytes on culture media with prevalence of $9.6 \%$. Tinea unguium (32\%) was the most prevalent infection seen in the community followed by tinea corporis $(27.45 \%)$, tenia capitis $(25.49 \%)$, tinea cruris $(13.72 \%)$ and tinea pedis $(0.98 \%)$.

T. mentagrophytes was the commonest etiological agent seen in $67.64 \%$ followed by $T$. rubrum $(25.49 \%)$ to cause dermatophytosis, whereas two dermatophytes which have shown phenotypic characters of dermatophytes of African origin like $T$. violaceum and $T$. soudanense from two different patients with tinea capitis and tinea unguium respectively were identified as T. rubrum. both isolates were slow growing without any macro or micro conidia. Studies have shown the emergence of $T$. violaceum in the population of native local origin in India as well as in different parts of world.(17-20) even though it is considered as dermatophyte of African Species, $(5,6,13,14)$ whereas many studies have shown $T$. soudanense is isolated in migrated African community in many parts of the world and rarely infecting the people of native origin. ${ }^{6,13,14)}$ In an attempt to isolate $T$. violaceum, and $T$. soudanense in Baltimore, Maryland, Shelley S. Magill et al have reported $88 \%$ of $T$. violaceum, and T. soudanense infection in migrated population of eastern Africa and west Africa living in America since three months to five years and $12 \%$ of infection U S origin population. (14) In a retrospective study conducted by Konstantin V. Grigoryan et al and Elizabeth Gaviria Morales et al in Rochester, Minnesota, United States and Southern Switzerland respectively to observe the presence of $T$. violaceum, and T. soudanense have reported the infection in $82.7 \%$ of Africans migrated to America, $4.93 \%$ in African Americans and $3.7 \%$ in White population in Rochester, Minnesota, United States, whereas in southern Switzerland $77.27 \%$ T. violaceum infection was seen in African patients and $15.90 \%$ infection in originally from Switzerland.(5,6) In the present study we have not found any such rare dermatophyte of African species. The possible reason for the decreased 
prevalence or absence of rare exotic dermatophytes of African origin in Siddi community, a migrated African population might be due to their existence in India since more than fivegeneration,(7) whereas others researchers have reported infection with dermatophyte of African species in the African origin population who are residing since one or twogeneration. $(5,6,13)$

A study conducted by Danielle Marcoux et al in 2018 have showed there was six fold rise in dermatophytes of African species in children of African origin residing in Canada since one or two generation.(13) A detailed study on this African origin population residing in other parts of India may reveal the presence geographically restricted dermatophytes. Antifungal susceptibility testing of isolates may also reveal the sensitivity pattern against antifungal drugs, and helps the clinician to treat dermatophytosis infection in such particular area.

In dermatophytes, ITS region of rDNA is used for species identification as well as for understanding phylogenetic relationship between the species.(21) This study confirms phenotypically identified dermatophyte of African species as T. rubrum, based on ITS region sequencing. Presence of these African anthropophilic dermatophyte species was observed in migrated African population in many other previous studies around the world. $(5,13,15)$ Whereas our study revealed absence of such rare exotic dermatophyte and T. mentagrophytes complex as prevalent etiological agent to cause dermatophytosis in Siddi tribal community as they stay in India since five generation and adapted to local and religious lifestyle.

\section{CONCLUSIONS}

Presence of rare African species was not seen in the migrated Siddi tribal community may be due to the existence of community in India for more than 5 generations and have adapted to local social and religious practices.

Financial or Other Competing Interests: None.

\section{REFERENCES}

[1] Liu D, Pearce L, Lilley G, et al. PCR identification of dermatophyte fungi Trichophyton rubrum, T. goudanense and T. gourvilii. J Med Microbiol 2002;51(2):117-22.

[2] Baranová Z, Kampe T, Dorko E, et al. Epidemiological and clinical aspects of dermatophytoses in Eastern slovakia: a retrospective three-year study. Cent Eur J Public Health 2018;26 Suppl:S72-5.

[3] Maraki S, Mavromanolaki VE. Epidemiology of dermatophytoses in crete, greece. Med Mycol J 2016;57(4):E69-75.
[4] Welsh 0, Welsh E, Ocampo-Candiani J, et al. Dermatophytoses in monterrey, méxico. Mycoses 2006;49(2):119-23.

[5] Morales EG, Iorizzo M, Lucchini GM, et al. Trichophyton violaceum: an emerging pathogen in Southern Switzerland. Dermatology 2019;235(5):434-9.

[6] Grigoryan KV, Tollefson MM, Olson MA, et al. Pediatric tinea capitis caused by trichophyton violaceum and trichophyton soudanense in Rochester, Minnesota, United States. Int J Dermatol 2019;58(8):912-5.

[7] Das R, Upadhyai P. Unraveling the population history of Indian Siddis. Genome Biol Evol 2017;9(6):1385-92.

[8] Thangaraj K, Ramana GV, Singh L. Y-chromosome and mitochondrial DNA polymorphisms in Indian populations. Electrophoresis 1999;20(8):1743-7.

[9] Hemashettar BM, Patil CS, Yenni VV, et al. Isolation of trichophyton yaoundei in India. Journal of Medical and Veterinary Mycology 1993;31(4):333-6.

[10] Hemashettar BM, Nadig VS. First isolation of trichophyton soudanense in India. Indian $\mathrm{J}$ Pathol Microbiol 1980;23(1):53-4.

[11] Kumar S, Stecher G, Tamura K. MEGA7: molecular evolutionary genetics analysis version 7.0 for bigger datasets. Mol Biol Evol 2016;33(7):1870-4.

[12] Lodhi AY. African settlements in India. Nordic J African Studies 1992;1(1):83-6.

[13] Marcoux D, Dang J, Auguste H, et al. Emergence of African species of dermatophytes in tinea capitis: a 17-year experience in a Montreal pediatric hospital. Pediatr Dermatol 2018;35(3):323-8.

[14] Magill SS, Manfredi L, Swiderski A, et al. Isolation of trichophyton violaceum and trichophyton soudanense in Baltimore, Maryland. J Clin Microbiol 2007;45(2):461-5.

[15] Tietz HJ, Hopp M, Graser Y. First isolation of trichophyton raubitschekii (syn. T. rubrum) in Europe. Mycoses 2002;45(1-2):10-4.

[16] Adamski Z, Kowalczyk MJ, Adamska K, et al. The first nonAfrican case of trichophyton rubrum var. raubitschekii or a urease-positive trichophyton rubrum in central Europe? Mycopathologia 2014;178(1-2):91-6.

[17] Upadhyay V, Kumar A, Singh AK, et al. Epidemiological characterization of dermatophytes at a tertiary care hospital in Eastern Uttar Pradesh, India. Curr Med Mycol 2019;5(1):1-6.

[18] Noronha TM, Tophakhane RS, Nadiger S. Clinicomicrobiological study of dermatophytosis in a tertiarycare hospital in North Karnataka. Indian Dermatol Online J 2016;7(4):264-71.

[19] Bhadoria AS, Kapil U, Bansal R, et al. Health-care utilization and expenditure patterns in the rural areas of Punjab, India. J Fam Med Prim Care 2017;6(2):169-70.

[20] Poluri LV, Indugula J, Kondapaneni S. Clinicomycological study of dermatophytosis in South India. J Lab Physicians 2015;7(2):84-9.

[21] Neji S, Trabelsi H, Hadrich I, et al. Molecular characterization of strains of the trichophyton verrucosum complex from Tunisia. Med Mycol 2016;54(8):787-93. 